\title{
Acute suppurative thyroiditis with transient hyperthyroidism in thalassemia child: an uncommon association in a common disease-a rare case report
}

\author{
Swaranjika Sahoo, Basudev Biswal ${ }^{*}$, Anuspandana Mohapatra and Rachita Sarangi
}

\begin{abstract}
Background: Thyroid infection is rare in paediatric age group in anatomically normal thyroid gland. However, acute suppurative thyroiditis (AST) is common in high-risk cases like thyroglossal duct remnant and thyroglossal pyriform sinus fistula. This may be associated with variable thyroid dysfunctions. Though transient hyperthyroidism is reported in some cases, its association was not documented in thalassemia child.

Case presentation: We are reporting an 8-year-old male child with a history of fever, pain, and left neck swelling for 5 days. He was evaluated and empirically started intravenous antibiotics (ceftriaxone, cloxacillin, and amikacin) along with other supportive treatment for localized signs of thyroid infection. Ultrasonography of the neck revealed intercommunicating pockets of collections with internal echoes in the left thyroid lobe. CT neck was done and suggested that the left lobe of the thyroid gland was replaced by hypodense lesions of fluid attenuation without any congenital abnormality of the thyroid gland. His thyroid function tests were suggestive of biochemical hyperthyroidism. He was treated with intravenous antibiotics and ultrasonography-guided fine-needle aspiration of pus. His pus culture showed growth of methicillin resistant Staphylococcus aureus. He also had microcytic hypochromic anaemia which was evaluated and found to have thalassemia trait. His biochemical hyperthyroidism normalized after completion of 2 weeks of treatment and required no intervention.

Conclusion: Acute suppurative thyroiditis is an uncommon clinical condition in an anatomically normal thyroid gland which could be associated with thyroid dysfunction. Its association in a thalassemia child is also not documented in literature. Clinical evaluation and proper history taking and non-invasive thyroid imaging are the cornerstone for diagnosis. Antibiotics and pus drainage are the mainstay management. Associated biochemical hyperthyroidism is transient and resolves without any specific medication in asymptomatic cases.
\end{abstract}

Keywords: Acute suppurative thyroiditis, Hyperthyroidism, Thalassemia, Case report

\section{Background}

Thyroid gland is an organ with a remarkable resistance to infection due to its profound vascular and lymphatic supply [1]. Fibrous encapsulation of the thyroid gland, separating it from other structures of the neck with abundance of iodine and hydrogen peroxide prevents

* Correspondence: biswalbasu@gmail.com

Department of Pediatrics, IMS and SUM Hospital, SOA Deemed to be University, Bhubaneswar, Orissa 751003, India growth of microorganisms [1]. Acute suppurative thyroiditis (AST) is thus an uncommon presentation in the paediatric age group [2]. Less than $0.7 \%$ of cases present as AST among thyroid disorders which may present with fever and painful neck swelling [3]. AST can be associated with thyroid dysfunctions which normalizes after management of infection [4]. 


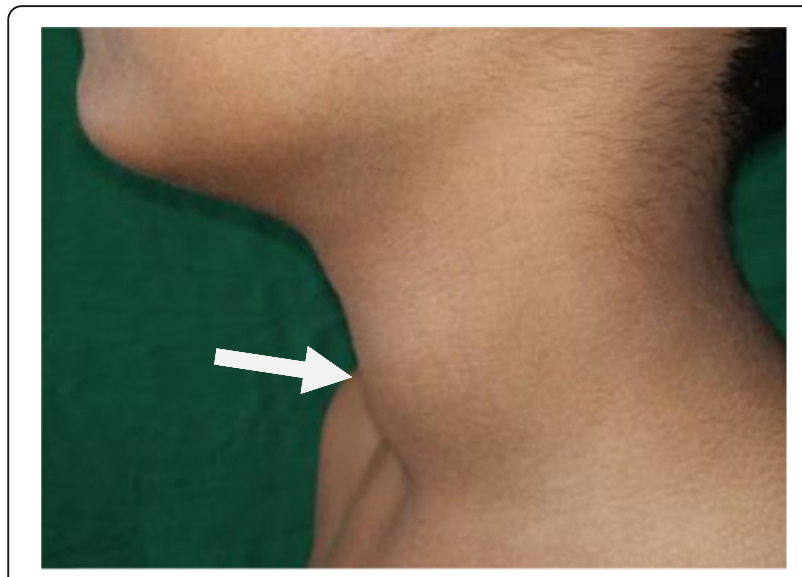

Fig. 1 Picture depicting swelling of neck over left side (white arrow)

\section{Case presentation}

An 8-year-old boy presented with high-grade fever, pain, and swelling of left side of neck region since 5 days. Child has positive consanguinity with no family history of any haemolytic anaemia. His body weight was $25 \mathrm{~kg}$ (25th-50th centile) and height was $125 \mathrm{~cm}$ (25th-50th centile) as per Indian Academy of Pediatrics growth chart. His temperature was $101.8^{\circ} \mathrm{F}$, heart rate $102 / \mathrm{min}$, respiratory rate $24 / \mathrm{min}$, and blood pressure $100 / 76$ $\mathrm{mmHg}$. On local examination, he had a soft, tender, fluctuant swelling of size $2 \mathrm{~cm} \times 2 \mathrm{~cm}$ noted in the left lobe of the thyroid gland (Fig. 1) with no local pus discharge and with regional cervical lymphadenopathy. Other systemic examinations were normal.
Initial laboratory investigations showed a haemoglobin level of $102 \mathrm{~g} / \mathrm{L}$, mean corpuscular volume of 64 $\mathrm{fl}$, total leucocyte count of $15.84 \times 10^{9} / \mathrm{L}$ with neutrophilia (82.6\%), Peripheral blood smear was suggestive of microcytic hypochromic anaemia with anisocytosis, poikilocytosis with neutrophilic leucocytosis. Total platelet count was $275 \times 10^{9} / \mathrm{L}$ and C-reactive protein $33.5 \mu \mathrm{g} / \mathrm{L}$. Ultrasonography of neck was suggestive of intercommunicating pockets of collections with internal echoes in left thyroid lobe with reactive left cervical lymph nodes (Fig. 2).Thyroid function tests were suggestive of hyperthyroidism [triiodothyronine $2.26 \mathrm{nmol} / \mathrm{L} \quad(2.01-3.12 \mathrm{nmol} / \mathrm{L})$, thyroxine 193.98 $\mathrm{nmol} / \mathrm{L} \quad(73.79-151.06 \mathrm{nmol} / \mathrm{L})$, and thyroidstimulating hormone $0.02 \mathrm{mIU} / \mathrm{L}(0.55-5.31 \mathrm{mIU} / \mathrm{L})$ ]. The anti-thyroid peroxidase (TPO) antibody test was negative. His haemoglobin electrophoresis reports were suggestive of beta thalassemia trait (HbA 95.4\%, $\mathrm{HbA}_{2}$ 4.6\%). Parents were evaluated for thalassaemia and only the mother was found to be beta thalassaemia trait. Child was started empirically on intravenous antibiotics (ceftriaxone, cloxacillin, and amikacin) along with other supportive treatment (paracetamol and serratiopeptidase). Contrast-enhanced computed tomography (CECT) of neck was done and was suggestive of thyroid abscess localized to left lobe without any congenital abnormality (Fig. 3). Ultrasonography-guided fine-needle aspiration of thyroid swelling was done and $3 \mathrm{cc}$ of pus was collected and sent for Gram stain, acid fast bacilli stain, pus culture, and sensitivity. Pus culture yielded growth of methicillin resistant Staphylococcus aureus. In view of

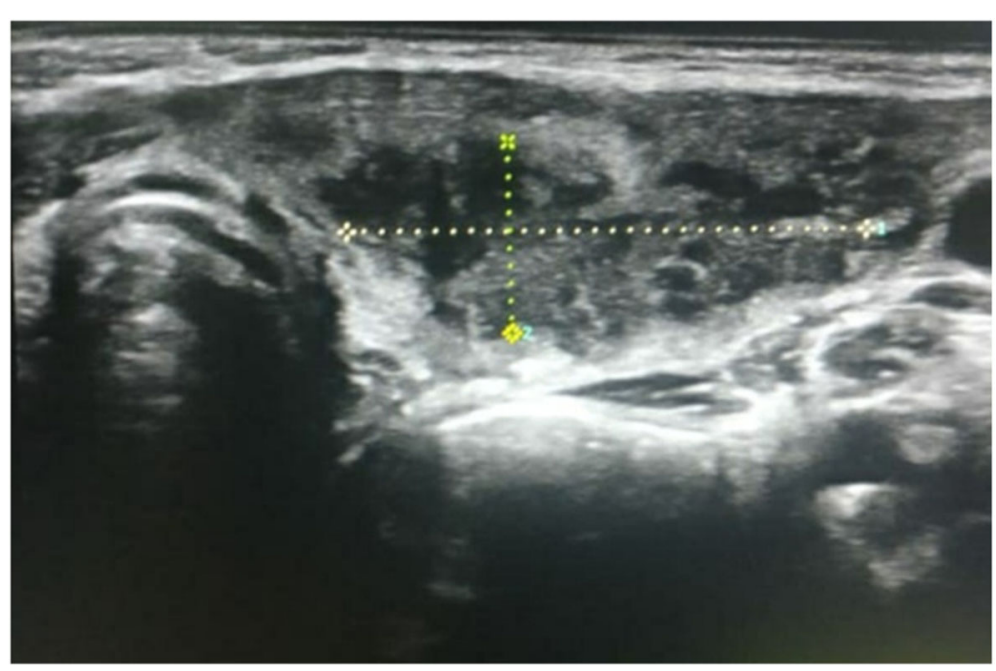

Fig. 2 Ultrasonography of neck suggestive of intercommunicating pockets of collections with internal echoes in left thyroid lobe (demarcated dotted area) 


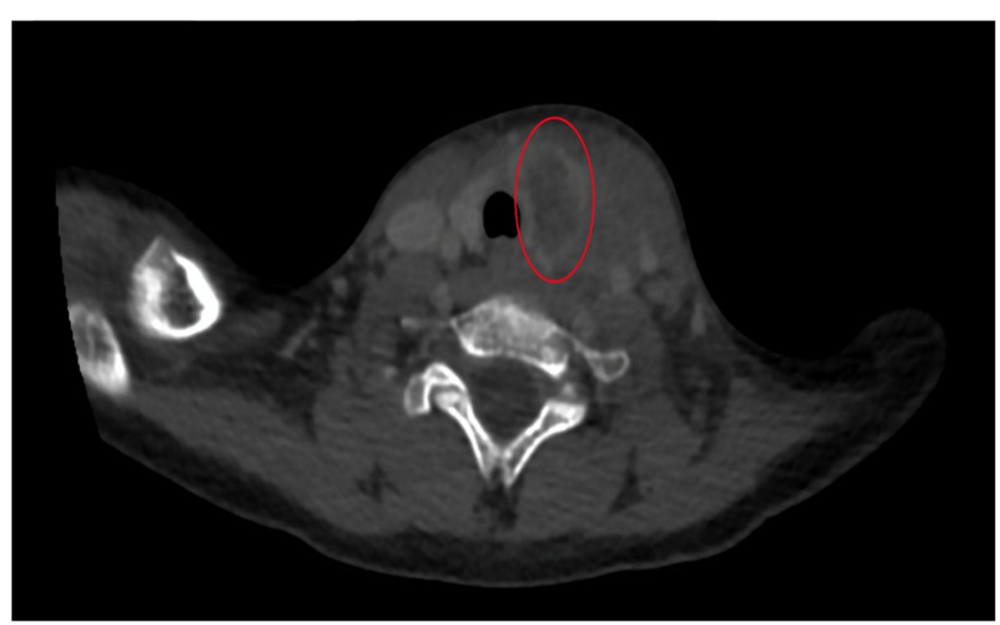

Fig. 3 CT scan of neck depicting left lobe of thyroid replaced by hypodense lesions of fluid attenuation (red demarcated circle area); features suggestive of acute suppurative thyroiditis

culture sensitivity report, injection cloxacillin was switched to injection of linezolid. Repeat thyroid function tests were normal after 2 weeks of antibiotic therapy and no intervention was started for transient hyperthyroidism.

\section{Discussion}

AST is associated with congenital anomalies of the 3rd and 4th brachial arch in 2-8\% of cases [2]. Patient usually presents with fever, painful swelling of neck, and rarely dysphasia, dysphonia [5]. AST can be associated with euthyroidism, hypothyroidism, and rarely hyperthyroidism [4, 6]. Hypothyroidism is also well documented in children with beta thalassaemia major [7]. However, we could not document association of transient hyperthyroidism in a thalassaemia child with AST after a profound literature search. Ultrasonographic study guides for the diagnosis and CT scan delineates underlying malformation, status of spread, and fistula formation [2]. The common infections causing AST are Staphylococcus aureus and Streptococcus pneumoniae, rarely Salmonella, Escherichia coli, and Haemophilus influenzae [3, 8, 9]. Primary modes of treatment are intravenous antibiotics and individualized surgical interventions like fine-needle aspiration or incision and pus drainage [9]. Most of the patients become asymptomatic with intravenous antibiotics, while some of them need ultrasonography-guided fine-needle aspiration [9]. Thyroid dysfunction during AST is transient and repeated testing of thyroid function should be done during the course of treatment [4]. As biochemical thyroid dysfunction during AST may resolve, active treatment should be reserved for symptomatic cases [4]. Though this is a single case report, a prospective study of similar cases would guide regarding their clinical presentation and management.

\section{Conclusion}

AST is an uncommon clinical condition in anatomically normal thyroid gland, which could be associated with thyroid dysfunction. AST in a child without any congenital malformation is also rarely documented [2] and its association with thalassemia is not documented .Clinical history and non-invasive thyroid imagings are the cornerstones for diagnosis [10]. Antibiotics and pus drainage are the mainstays of management $[9,10]$. ASTassociated biochemical hyperthyroidism is transient and resolves after treatment [4].

\section{Abbreviations}

AST: Acute suppurative thyroiditis; TPO: Thyroid peroxidase; CECT: Contrastenhanced computed tomography

\section{Acknowledgements \\ Not applicable}

Authors' contributions

SS conceptualized and drafted the initial manuscript. BB investigated, interpreted and revised the manuscript. AM reviewed, edited, and revised the manuscript. RS conceptualized and supervised the drafting of article. All the authors read and approved the final manuscript submitted and agreed to be accountable for all aspects of work.

\section{Funding \\ We did not receive any specific grant from funding agencies.}

Availability of data and materials Not applicable

Ethics approval and consent to participate

Institutional Ethical committee approval was taken for the case study and publication.

\section{Consent for publication}

Informed consent (verbal) was taken from the parent for participation and publication of image in view of COVID-19 pandemic.

Competing interests

The authors declare that they have no competing interests. 
Received: 2 June 2020 Accepted: 29 June 2020

Published online: 13 July 2020

References

1. Nishiyama $\mathrm{RH}$ (2000) Overview of surgical pathology of the thyroid gland. World J Surg 24:898-906

2. Shah S, Bhandary S, Natesh V, Chetri ST, Paudel D et al (2012) Thyroid abscess: a report of six cases. Bangladesh J Otorhinolaryngology 18:207-211

3. Paes JE, Burman KD, Cohen J, Franklyn J, McHenry CR, Shoham S et al (2010) Acute bacterial suppurative thyroiditis: a clinical review and expert opinion. Thyroid. 20:247-255

4. Panamonta O, Panombualert S, Panamonta M, Apinives C (2009) Acute suppurative thyroiditis with thyrotoxicosis. J Med Assoc Thail 92(10):1370-1373

5. Brent GA, Larsen PR, Davis TF (2008) Hypothyroidism and thyroiditis. In: Kronenberg HM, Melmed S, Polonsky KS, Larsen PR (eds) Williams text book of endocrinology. 11thed. Saunders Elsevier, Philadelphia, pp 377-410

6. Yoo CH, Kim YN, Shon CB, Park EH, Choi YS, Park YH et al (2008) A case of acute suppurative thyroiditis with thyrotoxicosis. Korean J Med 75:242-245

7. Upadya SH, Rukmini MS, Sundararajan S, Baliga BS, Kamath N (2018) Thyroid function in chronically transfused children with beta thalassaemia major: a cross-sectional hospital based study. Int J Pediatr 2018:9071213

8. Shah SS, Baum SG (2000) Diagnosis and management of infectious thyroiditis. Curr Infect Dis Rep 2:147-153

9. Kuzu F, Arpaci D, Acar FZ, Tiknak SP, Caknak GK, Celebi G, Comert F, Uygun SI, Bayraktaroglu T (2016) A case of suppurative thyroiditis caused by Salmonella presented with thyrotoxicosis. Indian J Med Microbiol 34:266-267

10. Sarfaraz M, Hasan SR, Qureshi Z (2018) Thyroid abscess in children: and the world gets stranger. J Rare Disord Diagn Ther 4:5. https://doi.org/10.21767/ 2380-7245.100175

\section{Publisher's Note}

Springer Nature remains neutral with regard to jurisdictional claims in published maps and institutional affiliations.

\section{Submit your manuscript to a SpringerOpen ${ }^{\circ}$ journal and benefit from:}

- Convenient online submission

- Rigorous peer review

- Open access: articles freely available online

- High visibility within the field

- Retaining the copyright to your article

Submit your next manuscript at $\boldsymbol{\nabla}$ springeropen.com 